\title{
JOURNAL OF BEHAVIORAL DECISION MAKING
}

\section{EDITOR}

GEORGE WRIGHT

University of

Strathclyde

UK

\section{ASSOCIATE EDITOR}

J. FRANK YATES

University of Michigan,

USA
The Journal of Behavioral Decision Making is a multidisciplinary journal with a broad base of content and style. The objective of the Joumal is to present and stimulate behavioral research on decision making and to provide a forum for the evaluation of complementary, contrasting and conflicting perspectives. These perspectives include: psychology, management science, sociology, political science and economics.

Papers published in the Journal will encompass, but not be limited to, the following areas:

- Individual decision making

* Management science and decision aids

* Interpersonal and small group decision making

- Organizational decision making

* Strategic decision making

- Social and political structuring of decision

- Behavioral economics

- Expert systems

- Consumer decision making

- Behavioral accounting

- Medical and clinical decision making

\section{SUBSCRIPTION DETAILS}

Volume 4 (1991) 4 Issues

Institutional Rate: Worldwide: US\$135.00

Personal Rate: UK: $£ 37.50$ Elsewhere: US\$67.50

Please send me a FREE sample copy of:

Behavioral Decision Making

NAME:

ADDRESS:

Please return to: Sarah Stevens, John Wiley \& Sons Ltd,

Baffins Lane, Chichester, West Sussex, PO19 1UD, UK

Telephone: (0243) 770257 Fax: (0243) 775878 


\title{
Decision Support Systems
}

\author{
The International Journal
}

\author{
Editors-In-Chief: \\ Hans-Jochen Schneider, ACTIS zentrale \\ Verwaltungs-GmbH, P.O. Box 800144 , \\ D-7000, Stuttgart 80, Germany \\ Andrew Whinston, MSIS Department, CBA \\ 5-202, University of Texas, Austin, TX 78712, \\ USA
}

\section{Assistant to the Editors-in-Chief: Dimitris Karagiannis, FAW-UIm, P.O. Box 2060, D-7900 Ulm, Germany}

\section{AIMS AND SCOPE \\ Education in the field of Decision Support Systems (DSS) is following two strictly separate curricula. On the one side there is a computer science curriculum which is very much technically oriented, while on the other side a curriculum of management science exists, aimed at educating business oriented people.}

Decision Support Systems covers these separate subject areas including

- Conceptual and Operational Bases of DSS;

- Normative Theories of Decision Making;

- Cognitive Science; - Positive Theorems of Decision Making; - Mathematical Modelling;

- Linguistics; - Simulation; - Algorithms;

- Reasoning Process; - Artificial Intelligence;

- Theoretical Models of DSS; - Implementation Techniques - Application Areas
The Journal encourages both further investigations by providing a forum for advances in the DSS field, and facilitates research by providing an efficient mechanism for researchers to keep up with the efforts of others. Decision Support Systems therefore serves as a forum for:" Researchers and Developers of DSS * Researchers and Practitioners in Computer Science, Management and Business Administration * Computer Manufacturers * Proprietary Software Developers - Managers in Industry, Commerce and Public Administration

The inclusion of survey papers promotes a broader understanding of the various facets of DSS research and signals research ideas that are ready for application. Notices of meetings, abstracts of selected research reports and reviews of books are also published.

ABSTRACTED/INDEXED IN: Cambridge Scientific Abstracts, INSPEC, ISI, ACM Computing Reviews, Engineering Abstracts, UMI Data Courier

Subscription Information:

1991: Volume 7 in 4 issues

Price: US $\$ 193.50$ / Dfl. 325.00

(postage/handling included)

ISSN: 0167-9236

The Dutch Guilder (Dfl.) price is definitive. USS price is subject to exchange ratefluctuations.

NORTH-HOLLAND

(An Imprint of Elsevier Science Publishers B.V.)

\section{Coupon for a free sample copy of Decision Support Systems}

Please send this form (or a photocopy) to Elsevier Science Publishers

Attn: H.A.C. Gierveld

P.O. Box 1991

1000 BZ Amsterdam, The Netherlands in the USA and Canada:

Elsevier Science Publishing Co. Inc.

Attn: Journal Information Center

655 Avenue of the Americas

New York, NY 10010, USA

Name

Professional Address 


\section{Introducing}

\section{The Computer Journal}

The international journal of information technology and computer applications Published for the British Computer Society by Cambridge University Press

Editor-in-Chief P Hammersley,Middlesex Polytechnic, The Burroughs, Hendon, London NW4 4BT, UK

"This journal is a valuable addition to every good collection in the computer sciences"

\section{MAGAZINES FOR LIBRARIES}

\section{Coverage}

The Computer Journal is one of the world's most eminent periodicals in the field of information technology and computer applications. Its coverage is unmatched by any other computing periodical. It includes advanced programming, computer science theory, databases, hardware and logic design and business applications. It also covers the newer disciplines such as parallel computing, object-oriented programming, logic programming and electronic publishing. Papers are always in the mainstream of new developments; their results are significant and far reaching; above all they are readable.

\section{Type of Articles Published}

The Computer Journal publishes original research papers, practical accounts of the latest developments and their likely impact, shorter communications, correspondence about recently published articles, and review articles.

The quality and scope of The Computer Journal can be seen from just a selection of recent and forthcoming articles. Send for a free sample copy and see for yourself!

\section{Special Issues}

In recent years the number of excellent papers submitted to The Computer Journal has grown enormously. The editors have therefore introduced a new method for selecting papers to be published: the bimonthly issues now identify state-of-the-art themes and publish new papers of general interest related to those themes. This will maintain The Computer Joumal as a leading medium in all aspects of computer science and computer applications. Most issues use only half the available space for the theme papers, and papers of a more general nature take up the rest of the space. All papers will still be refereed in the usual way and the emphasis is on the highest standards.

Cambridge
\$o Joumals

Cambridge University Press

The Edinburgh Building, Cambridge CB2 2RU, England 40 West 20th St, New York, NY 10011-4211, USA
Recent Articles

AParallel Prolog Abstract Machine and its Multi-Transputer Implementation

P. KACSUK

Prolog in Practical Compiler Writing

J. PAAKKI

Constraint Maintenance as a Data Model Design Criterion L. Orman

AModel for the Stability Analysis of Maintenance Strategies for Linear List

F. B. Bastani, I-R Chen And W. HILAL

Empirical Study of the Expected Running Time of Shellsort M. A. WIESS

A Neural Network Simulating System

J-L. WU AND S-T. ChENC

Why you must read The Computer Journal...

Whatever your level and area of interest, you'll find The Computer Journal readable, up-to-date, informative, exciting and topical. It gives independent and authoritative coverage of the most important and significant new areas of research and their applications.

\section{Subscription information}

The Computer Journal (ISSN 0010-4620), Volume 34: February, April, June, August, October and December 1991. $£ 174$ for UK subscribers, $£ 185$ for subscribers elsewhere.

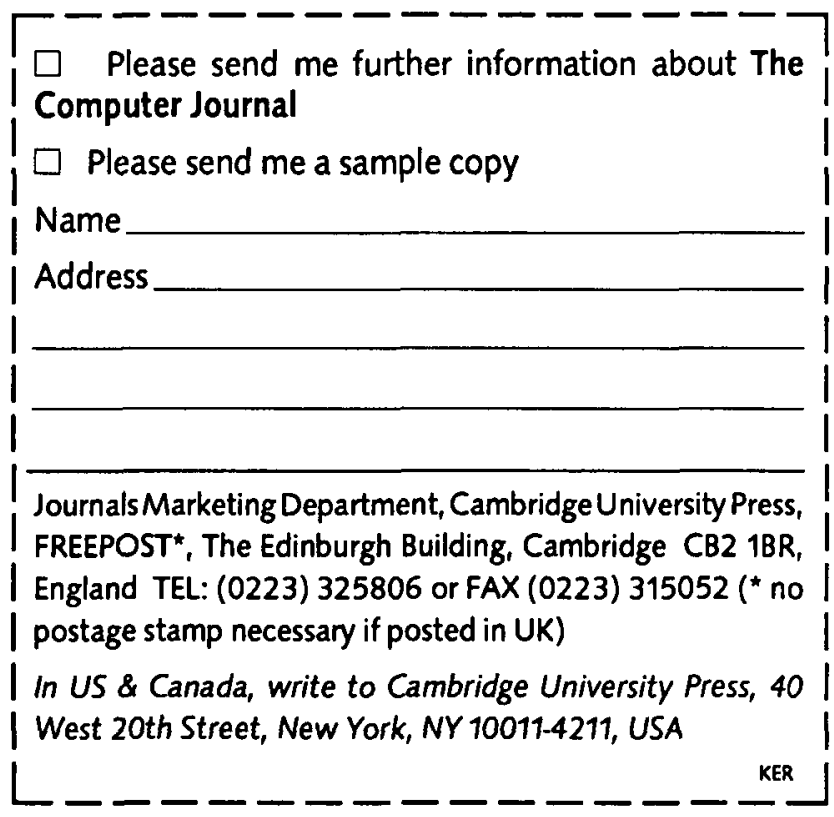




\section{Introducing...}

\section{Robotica}

International Journal of Information, Education and Research in Robotics and Artificial Intelligence

Editor

Professor J Rose, Honorary Director of the World Organisation of Systems and Cybernetics

Deputy Editors

Dr EW Kent, Philips Laboratories, BriarcliffManor, NY, USA

Professor R A Jarvis, Monash University, Victoria, Australia

Professor Y Umetani, Tokyo Institute of Technology, Japan

Dr P Coiffet, CRIIF, Paris, France

Editor, Robotics Reports and Surveys

Professor B H Rudall, University College of North Wales, Bangor, UK

There is increasing interest in automation, particularly in industry. Robotica, published by Cambridge University Press, is now the most prestigious journal of its kind in the world. It provides an international forum and encourages developments by covering all aspects of this important subject area. It endows robotics with an authoritative, competent and dedicated journal to serve industry, research and education.

Increased page extent and new look for 1991

The quantity of excellent material that is now received for publication is such that we have increased the extent of Robotica by almost $20 \%$ for 1991 (and over 100\% since its inception in 1982). So now you have even more quality articles in your quarterly issues. And in order to reflect the forwardlooking attitude of the journal and its editors, Robotica has been given a face lift. We hope that you like the new design.
'So often students will ask "What courses of study do you recommend as preparation for a career in robotics?"...read Robotica.'

\section{J F EncelBerger, President, Unimation Inc.,} CONNECTICUT

Why you should subscribe to Robotica

- As well as original papers, Robotica contains Reports and Surveys, Book Reviews, Conference News, Announcements and Letters to the Editor, so you can get a comprehensive view of current developments

- Compared with other periodicals in the field Robotica represents excellent value for money

- Robotica covers both theoretical and practical issues in a wide context

- Papers are of a very high scientific quality and have gone through rigourous refereeing

- Papers are received from all over the world, not just from the US and Japan as in many other journals

- The spread of subjects covered provides the most accurate picture of current worldwide activity that you are likely to be able to get

\section{Subscription Information}

Volume 9 in 1991, published in January, April, July and October. Individuals $£ 45$, UK institutions $£ 95$, institutions elsewhere $£ 99$, airmail $£ 16$ per year extra. ISSN 0263-5747
Please send me a free sample copy of Robotica

Please send me a free 1991 Journals Catalogue

Name

Address

KER
Send to: Journals Marketing Department, Cambridge University Press, FREEPOST*, The Edinburgh Building, Cambridge CB2 1BR, England TEL: (0223) 325806 or FAX: (0223) 315052 (* no postage stamp necessary if posted in UK) In US \& Canada, write to Cambridge University Press, 40 West 20th Street, New York, NY 10011-4211, USA
A Cambridge Tournals 


\section{The knowledge engineering review}

\section{Notes for Contributors}

Contributions for publication should be addressed to Dr John Fox, Editor, The Knowledge Engineering Review, Biomedical Computing Unit, PO Box 123, Lincoln's Inn Fields, London WC2A 3PX, England, Dr Peter Jackson, North American Editor, McDonnell-Douglas Research Lab, Artificial Intelligence Group, PO Box 516, St Louis, MO 63166, USA, or may be submitted through a member of the Editorial Advisory Board (addresses inside front cover). Submission implies that the manuscript has not been published previously nor currently submitted for publication elsewhere.

All contributions, whether articles, correspondence or reviews, must be sent in triplicate and typed on one side of the paper, with wide margins and double-line spacing throughout. Any minor corrections should be made neatly in the typescript, leaving the margins clear. The author is invited to nominate up to five possible referees, who will not necessarily be used.

Articles must be accompanied by a brief, informative rather than indicative, abstract. Headings should be set out clearly but not underlined. Primary headings should be in lower case, at margin, with arabic numeral; subheadings should be numbered 2.a., 2.b., etc., and tertiary headings, 2.a.1., 2.a.2. No cross-references should be given by page number, but 'above' and 'below' should be used with the section specified, e.g. Section 2.a.2. The SI system of units should be used. The author should mark in the margin of the manuscript where figures and tables may be inserted. References to points in larger works should, where possible, quote the page reference, e.g. Ager, 1981, p. 102.

Tables should be typed with double-line spacing on sheets separate from the running text. Each table must have a caption that will make the data in the table intelligible without reference to the text.

Illustrations should be drafted for reproduction as full page $(148 \mathrm{~mm})$ width. Originals should normally be drawn at twice final area and must be sent in a flat package; larger drawings may delay publication. Lettering should be of a size so that when reduced the smallest lower-case letters will not be less than about $1 \mathrm{~mm}$. Avoid gross disparities in lettering size on a drawing. Duplicates of illustrations should be sent, and may be prints or, preferably, photocopies reduced to final size. Illustrations in the text, both line drawings and photographs for halftone reproductions, will be referred to as figures (Fig. 2, 2a, etc.). Folding plates will not be accepted. Figures composed of photographs should be glossy prints presented at publication scale. Figure captions must be typed with double-line spacing on sheets separate from the running text.

The accuracy of references is the responsibility of authors. References must be double-spaced and spelt out in full, e.g.

Gale, W A, ed 1986. Artificial Intelligence and statistics, Reading, Massachusetts: Addison-Wesley

Pearl, J 1984. Heuristics. Intelligent search strategies for problem solving, Reading, Massachusetts: AddisonWesley

Tie-Cheng Wang and Bledsoe, W W, 1987. "Hierarchical deduction" Journal of Automated Reasoning 3 (1) ppl-34.

Pau, L F, 1986. "Survey of expert systems for fault detection, test generation and maintenance" Expert Systems, $3(2)$ pp 100-111.

Twenty Five offprints of each paper will be provided free of charge. Additional offprints may be purchased according to a set scale of charges if ordered when the proofs are returned. 


\section{The knowledge engineering review}

\section{VOLUME 6 NUMBER 2 JUNE 1991}

\section{Contents}

Towards knowledge-based tutors: a survey and appraisal of intelligent tutoring systems

TOMAS SOKOLNICKI

Case research on knowledge acquisition: observations and lessons

CHRISTINE CHAN and IZAK BENBASAT

Book reviews

From the journals

\section{CAMBRIDGE UNIVERSITY PRESS}

Published by the Press Syndicate of the University of Cambridge

The Pitt Building, Trumpington Street, Cambridge CB2 1RP

40 West 20th Street, New York, NY 10011-4211, USA

10 Stamford Road, Oakleigh, Melbourne 3166, Australia

\section{Typeset by Paston Press, Loddon}

Printed in Great Britain by Henry Ling Ltd, Dorchester 